\title{
Uplift mobilisation resistance of subsea pipelines in loose sand
}

\author{
A. IVANOVIĆ* and J. OLIPHANT†
}

\begin{abstract}
Upheaval buckling (UHB) is a well-known phenomenon associated with buried high-pressure hightemperature pipelines. A large number of research studies have been undertaken in the last two decades on developing reliable uplift resistance mobilisation models from which the current standards and recommendations are based. This paper examines Technip's extensive database consisting of experimental and numerical studies concerning sandy backfills only. The peak uplift mobilisation distances obtained are compared with the current DNV recommendations and a recent experimental study undertaken at the University of Cambridge. The trends obtained indicate differences associated specifically with the lower backfill cover depths and suggest that the current recommendations need to be updated. A new improved peak mobilisation distance model, which is able to capture the relevant data with a distinction made between very loose and loose sand backfill, is offered.
\end{abstract}

KEYWORDS: buried structures; offshore engineering; pipelines; sands; standards

ICE Publishing: all rights reserved

\section{NOTATION}

$\begin{array}{ll}D & \text { pipe diameter } \\ H & \begin{array}{l}\text { cover height, defined as vertical distance from top of } \\ \text { backfill to top of pipe } \\ \end{array} \\ \delta_{\mathrm{f}} & \begin{array}{l}\text { mobilisation distance } \\ \text { peak mobilisation }\end{array}\end{array}$

\section{INTRODUCTION}

The transport of hydrocarbon products offshore in shallow water is generally through trenched subsea pipelines. These pipelines are typically at higher temperatures and pressures than the ambient surrounding environment. This causes the pipeline to expand, which induces an axial compressive force along the pipeline as the backfill on top of the pipeline restrains its movement. This force and any imperfections in the pipeline can result in vertical upheaval buckling (UHB) where, in the worst case, the pipeline can protrude above the seabed.

Imperfections in a pipeline trench are defined as vertical out-of-straightness (OoS) events, which indicate the locations where UHB is most likely to occur as the force required to buckle at an imperfection is less than that for a flat pipeline. OoS events can be caused by natural imperfections such as initial seabed conditions, boulders and sand waves. However, the main cause of OoS events is from the trenching operation due to variations in trencher performance (e.g. stop/start plough operation and collapsed or slumped material from the trench walls getting under the pipeline)

Figure 1 shows the effective axial force developed along a length of a pipeline. At the ends, where the pipeline is free to expand, the axial force reduces to zero. It can be seen from the plot that, in sections, the effective axial force is greater than the critical force for various prop height

Manuscript received 5 September 2013; first decision 15 October 2013; accepted 14 July 2014.

Published online at www.geotechniqueletters.com on 29 August 2014.

*School of Engineering, University of Aberdeen, Aberdeen, UK $\dagger$ Technip, Westhill, UK imperfections and hence these would be susceptible to UHB. UHB mitigation can be effective when backfill is placed on top of the pipeline within the trench. The backfill material will provide a resistance to pipeline movement, which will depend on the type of backfill used and how it is placed in the trench. The main methods of pipeline burial offshore are

- jet trenching, in which a series of high-pressure water jets liquefy the soil and the pipeline sinks

- pipeline ploughing, where a tool with a cutting share is towed along the seabed to form an open trench which is then backfilled upon installation of the pipeline.

Sand backfill formed through jet trenching will be in a very loose condition with relative density (RD) typically $<10 \%$. On the other hand, mechanically placed sand backfill will typically be in a loose to medium dense condition, represented as $10 \%<\mathrm{RD}<40 \%$.

The uplift resistance offered by a sand backfill depends on the upward movement of the pipeline. This vertical pipeline movement required to fully mobilise the uplift resistance is an important parameter for UHB, as the critical buckling force depends on the vertical upward stiffness of the sand backfill (Randolph \& Gourvenec, 2011). This peak mobilisation distance also adds to the imperfection height mentioned earlier. Hence, the greater the mobilisation distance - or the lower the upward stiffness - then the lower the critical buckling force and the longer the length of pipeline susceptible to buckling. As such, underestimating the mobilisation distance could result in an unsafe design as the resistance provided by the backfill at critical sections along the pipeline may not be sufficient to resist the buckling force. Expensive remedial measures (e.g. rock dump or concrete mattresses placed on top of the backfill) would therefore be required to mitigate the excess buckling force.

The topic of mobilisation distance of sand backfill has attracted significant research interest. This has resulted in a number of small-scale centrifuge studies (e.g. Dickin, 1994; White et al., 2001), $1 \boldsymbol{g}$ laboratory studies (e.g. Schaminee et al., 1990; Bransby et al., 2002) and numerical modelling approaches (e.g. Dickin \& Laman, 2007; Cheuk et al., 2008).

Current design guidelines for uplift resistance suggest that the peak uplift resistance in sandy backfill is mobilised 


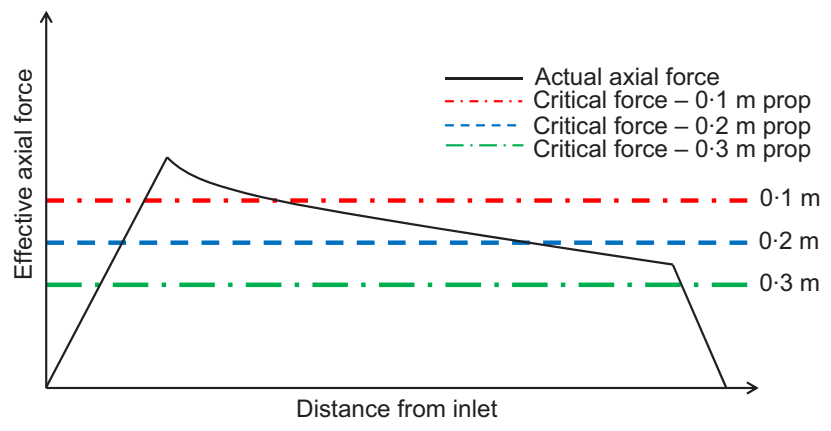

Fig. 1. Critical buckling force profile

when the upward movement of the pipe reaches $0 \cdot 5-0 \cdot 8 H \%$, where $H$ is the cover height defined as the vertical distance from the top of the backfill to the top of the pipe (DNV, 2007).

Palmer et al. (2003) reported that the peak uplift resistance shows good agreement between centrifuge and $1 \boldsymbol{g}$ modelling tests but indicated inconsistencies in the dimensionless mobilisation displacement because of localised shear zone formation. As a result, caution should be taken when centrifuge data of mobilisation distances are used for design purposes.

A few studies have investigated rate effects associated with how quickly water drains from the sediment. Bransby \& Ireland (2009) indicated that if uplift speeds are less than $0 \cdot 167 \mathrm{~mm} / \mathrm{s}$, then saturated loose clean sand will behave as dry loose sand (i.e. fully drained condition). However, when the rate of testing exceeds this limiting value, partially drained conditions will apply and this will affect the peak mobilisation displacement. Williams et al. (2013) showed that the mobilisation displacement will increase for speeds in the range $0 \cdot 002-5 \mathrm{~mm} / \mathrm{s}$.

A recent full-scale experimental study was undertaken at the University of Cambridge in sandy backfill (Thusyanthan et al., 2010; Wang et al., 2012) to investigate the uplift stiffness response of pipelines buried in both saturated and dry sand. The results showed that the ratio of mobilisation distance to peak uplift resistance depends on $H / D$ and exceeds the recommendations stated in DNV-RP-F110 (DNV, 2007). Based on experimental data obtained from their study and a few studies found in the literature, Thusyanthan et al. (2010) proposed a new equation for peak mobilisation in loose sand as a function of $H / D$

$$
\frac{\delta_{\mathrm{f}}}{D}=0.02 \exp \left(0 \cdot 5 \frac{H}{D}\right)
$$

Thusyanthan et al. (2010) compared their test data with centrifuge experiments (Dickin, 1994), results from strip anchor plates (Dickin \& Laman, 2007) and the study undertaken by White et al. (2001). As mentioned before, Palmer et al. (2003) indicated that centrifuge test data may not be representative of the mobilised displacement associated with upheaval bucking. Although Dickin \& Laman
(2007) suggest that similar behaviour may be expected for both anchor plates and pipelines, they also highlight that 'significant differences do exist in displacements to failure'. In addition, the data presented by Thusyanthan et al. (2010) are on a log scale, which minimises any discrepancy between the datasets for large values of $H / D$ than if a linear scale was used. The majority of the tests undertaken by Thusyanthan et al. (2010) focused on loose sand with $10 \%<\mathrm{RD}<40 \%$. A few tests on very loose sand with $\mathrm{RD}<10 \%$ were undertaken by Schaminee et al. (1990). More recently, studies reported by Byrne et al. (2013) and Williams et al. (2013) have provided a comprehensive dataset of approximately 60 tests performed on very loose sand $(0 \%<\mathrm{RD}<17 \%)$.

This paper attempts to address the lack of clear and consistent guidelines related to the vertical distance required to fully mobilise the peak uplift resistance of a pipeline for shallow burial depths of $H / D<3.5$ and very loose and loose sand backfill for dry and saturated conditions.

\section{DATA ANALYSIS}

The Technip database comprises both experimental and numerical data gathered from research studies undertaken since 1995. The database contains the published studies undertaken by Matyas \& Davis (1983), Trautmann et al. (1986), Schaminee et al. (1990), Dickin (1994), Ng \& Springman (1994), White et al. (2001), Martindill (2005), Cheuk et al. (2008), Thusyanthan et al. (2010), Wang et al. (2012) and Byrne et al. (2013). It also contains test results commissioned directly by Technip, called Technip A and Technip B (Technip OED, 2003).

The general relationship used for design is defined through the tri-linear uplift resistance model defined in DNV-RP-F110 (DNV, 2007), which is based on the mobilisation distance $\delta_{\mathrm{f}}$ and parameters $\alpha$ and $\beta$ shown in Table 1; DNV-RP-F110 further indicates that $\delta_{\mathrm{f}}$ is independent of $H / D$. The peak mobilisation $\delta_{\mathrm{f}}$ was examined for the Technip database over a range of $H / D$ values. In order to observe the data for shallow depths, $\delta_{\mathrm{f}}$ was normalised with diameter $D$.

\section{RESULTS AND DISCUSSION}

The data obtained from the Technip database were analysed using only complete datasets. Peak mobilisation values for some datasets were not available and consequently these were not included. Table 2 gives an overview of the data used in this analysis, giving an indication of the condition of the soil, RD, number of tests undertaken and rate of pipeline displacement (where available).

Tests undertaken on loose sand only were included in this analysis. Centrifuge test results were not included following the recommendation of Palmer et al. (2003) as they are not representative of the peak displacements found in $1 \boldsymbol{g}$ tests.

Figure 2 presents a complete set of the data available for loose sand ( $\mathrm{RD}<40 \%$ ) compared with the current DNVRP-F110 (DNV, 2007) recommendations. Some data are also marked 'sub' and 'dry', indicating tests undertaken in

Table 1. DNV-RP-F110 (DNV, 2007) parameters for sand

\begin{tabular}{l|l|c|r|r|r}
\hline Backfill & \multicolumn{1}{|c|}{ Condition } & $\begin{array}{c}\text { Mobilisation } \\
\text { distance, } \delta_{\mathrm{f}}: \mathrm{mm}{ }^{\mathrm{a}}\end{array}$ & $\alpha$ & $\beta$ & Limitations \\
\hline Sand & Loose & $0 \cdot 5-0 \cdot 8 H^{\circ} \%$ & $0 \cdot 75-0 \cdot 85$ & $0 \cdot 2$ & $3 \cdot 5 \leq H / D \leq 7 \cdot 5$ \\
Sand & Medium/dense & $0 \cdot 5-0 \cdot 8 H^{\circ} \%$ & $0 \cdot 65-0 \cdot 75$ & $0 \cdot 2$ & $2 \cdot 0 \leq H / D \leq 8 \cdot 0$ \\
\hline
\end{tabular}

${ }^{\mathrm{a}} \delta_{\mathrm{f}}$ given in the code as $0 \cdot 005-0 \cdot 010 H$ 


\begin{tabular}{|c|c|c|c|c|c|c|c|c|c|c|c|c|c|c|c|}
\hline $\begin{array}{l}\vec{E} \\
\text { E } \\
\tilde{\Xi}\end{array}$ & & & 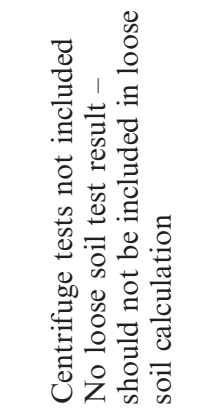 & & & & & & & & & & & \multicolumn{2}{|c|}{ 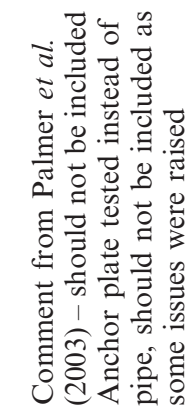 } \\
\hline 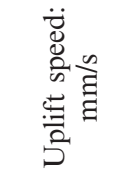 & $\begin{array}{l}\hat{O} \\
\dot{0}\end{array}$ & & $\begin{array}{l}\overrightarrow{\bar{o}} \\
\dot{0}\end{array}$ & $\begin{array}{l}1 \\
0 \\
\dot{0} \\
1 \\
8 \\
\dot{0}\end{array}$ & & $\stackrel{m}{\tilde{\theta}}$ & $\stackrel{m}{\tilde{0}}$ & & $\begin{array}{l}1 \\
\stackrel{8}{0} \\
\dot{0}\end{array}$ & $\frac{\infty}{\frac{1}{1}}$ & $\begin{array}{l}n \\
\hat{j} \\
n \\
\hat{o} \\
0\end{array}$ & $\begin{array}{l}\dddot{n} \\
\vdots \\
0\end{array}$ & $\begin{array}{l}\mathscr{n} \\
\dot{8} \\
\dot{0}\end{array}$ & $\begin{array}{l}\hat{\sigma} \\
\dot{0}\end{array}$ & $\begin{array}{l}\hat{\delta} \\
\dot{0}\end{array}$ \\
\hline 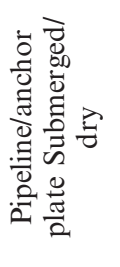 & 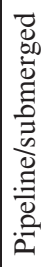 & 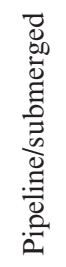 & 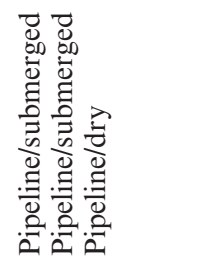 & 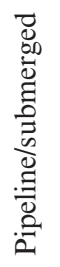 & 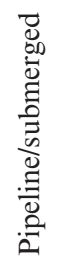 & 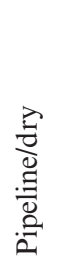 & 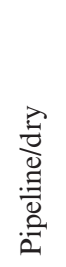 & 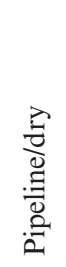 & 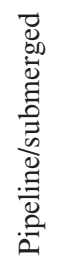 & 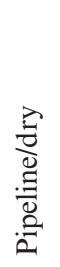 & 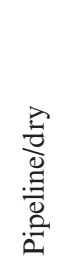 & 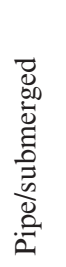 & 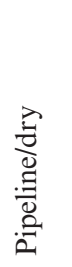 & $\begin{array}{l}\stackrel{0}{\Xi} \\
: \\
:\end{array}$ & 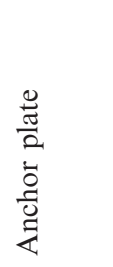 \\
\hline 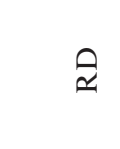 & $\begin{array}{l} \pm \\
\dot{0} \\
0 \\
0 \\
\dot{0}\end{array}$ & $\begin{array}{l}\vec{T} \\
\dot{0} \\
\frac{1}{0}\end{array}$ & 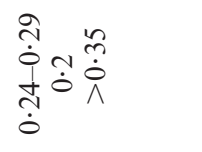 & $\begin{array}{l}\vec{r} \\
\dot{0} \\
\frac{1}{\dot{0}}\end{array}$ & $\begin{array}{l}\vec{r} \\
\dot{0} \\
\dot{0}\end{array}$ & $\stackrel{\vec{d}}{\tilde{0}}$ & $\overrightarrow{\widetilde{\sigma}}$ & $\begin{array}{l}\infty \\
\stackrel{1}{0} \\
\stackrel{1}{1} \\
\dot{0}\end{array}$ & & $\frac{N}{0}$ & $\begin{array}{c}\hat{\hat{\jmath}} \\
\dot{0}\end{array}$ & $\stackrel{n}{0}$ & & & $\begin{array}{l}\hat{0} \\
\dot{0}\end{array}$ \\
\hline $\begin{array}{l}\Xi \\
\Xi \\
\dot{\phi} \\
\dot{\theta}\end{array}$ & $\begin{array}{l}m \\
\dot{0} \\
\tilde{\imath} \\
\dot{0}\end{array}$ & $\begin{array}{l}m \\
\dot{0} \\
n \\
\dot{0}\end{array}$ & $\begin{array}{l}m a \\
\dot{0} \dot{0} \\
\frac{1}{0} \\
\dot{0} \dot{0}\end{array}$ & $\begin{array}{l}a \\
\dot{0} \\
\tilde{a} \\
\dot{0}\end{array}$ & $\begin{array}{l}\frac{n}{\dot{0}} \\
\dot{0}\end{array}$ & $\ddot{0}$ & $\ddot{0}$ & $\stackrel{n}{0}$ & & & & $\frac{\infty}{0}$ & $\stackrel{\infty}{0}$ & & \\
\hline $\begin{array}{l}\Xi \\
\Xi \\
\ddot{0}\end{array}$ & $\frac{n}{0}$ & $\frac{n}{0}$ & 눙 & $\overrightarrow{0}$ & $\stackrel{8}{\circ}$ & $\dot{0}$ & $\dot{0}$ & $\dot{0}$ & & & & & & & \\
\hline$\overline{\bar{\delta}}$ & $\begin{array}{l}=\overline{0} \\
0 \\
0 \\
0 \\
0 \\
0 \\
2 \\
0 \\
0 \\
j\end{array}$ & $\begin{array}{l}\overline{0} \\
\infty \\
0 \\
0 \\
0 \\
.\end{array}$ & 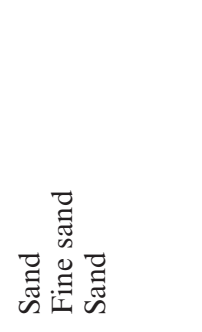 & 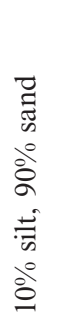 & 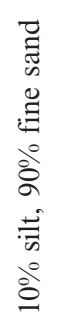 & 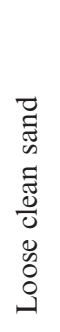 & 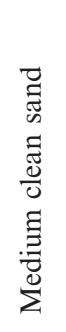 & $\begin{array}{l}\vec{\Xi} \\
\tilde{W}\end{array}$ & 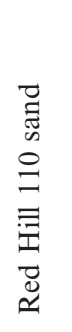 & $\frac{\mathfrak{a}}{\stackrel{a}{a}}$ & 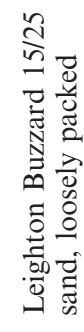 & & & 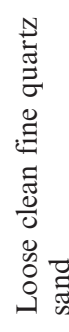 & 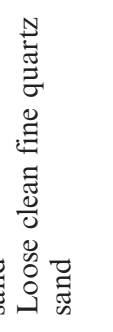 \\
\hline 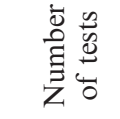 & $m$ & 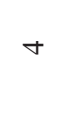 & in in & $\nabla$ & $\nabla$ & 6 & $\sim$ & $n$ & 2 & ¿ి & in & $\infty$ & $N$ & $\nabla$ & $r$ \\
\hline$\stackrel{\vec{D}}{\stackrel{0}{\leftrightarrow}}$ & 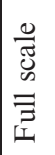 & 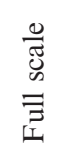 & 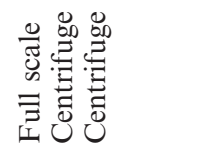 & 苞 & 氖 & 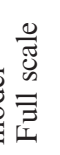 & $\begin{array}{l}\frac{0}{\tilde{J}} \\
\stackrel{m}{\Xi} \\
\bar{\Xi}\end{array}$ & $\begin{array}{l}\stackrel{0}{\tilde{J}} \\
\text { מू }\end{array}$ & ๑ే & 过 & 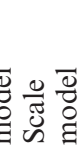 & $\begin{array}{l}\frac{0}{\tilde{U}} \\
\frac{m}{3} \\
\bar{\Xi}\end{array}$ & 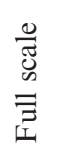 & : & $\underset{:}{\stackrel{\infty}{\Xi}}$ \\
\hline 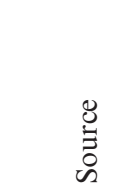 & 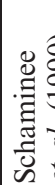 & 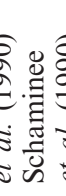 & 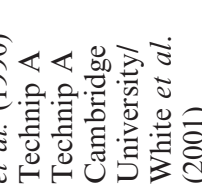 & 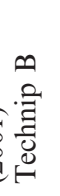 & 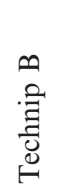 & 壱 & 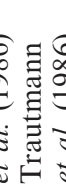 & 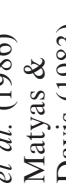 & 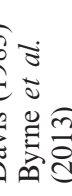 & 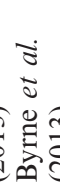 & 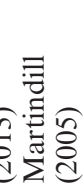 & 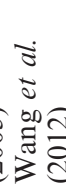 & 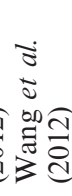 & $\begin{array}{l}\stackrel{f}{\sigma} \\
\stackrel{\Xi}{\Xi} \\
\frac{\Xi}{0} \\
\frac{0}{0}\end{array}$ & 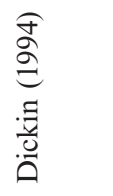 \\
\hline
\end{tabular}




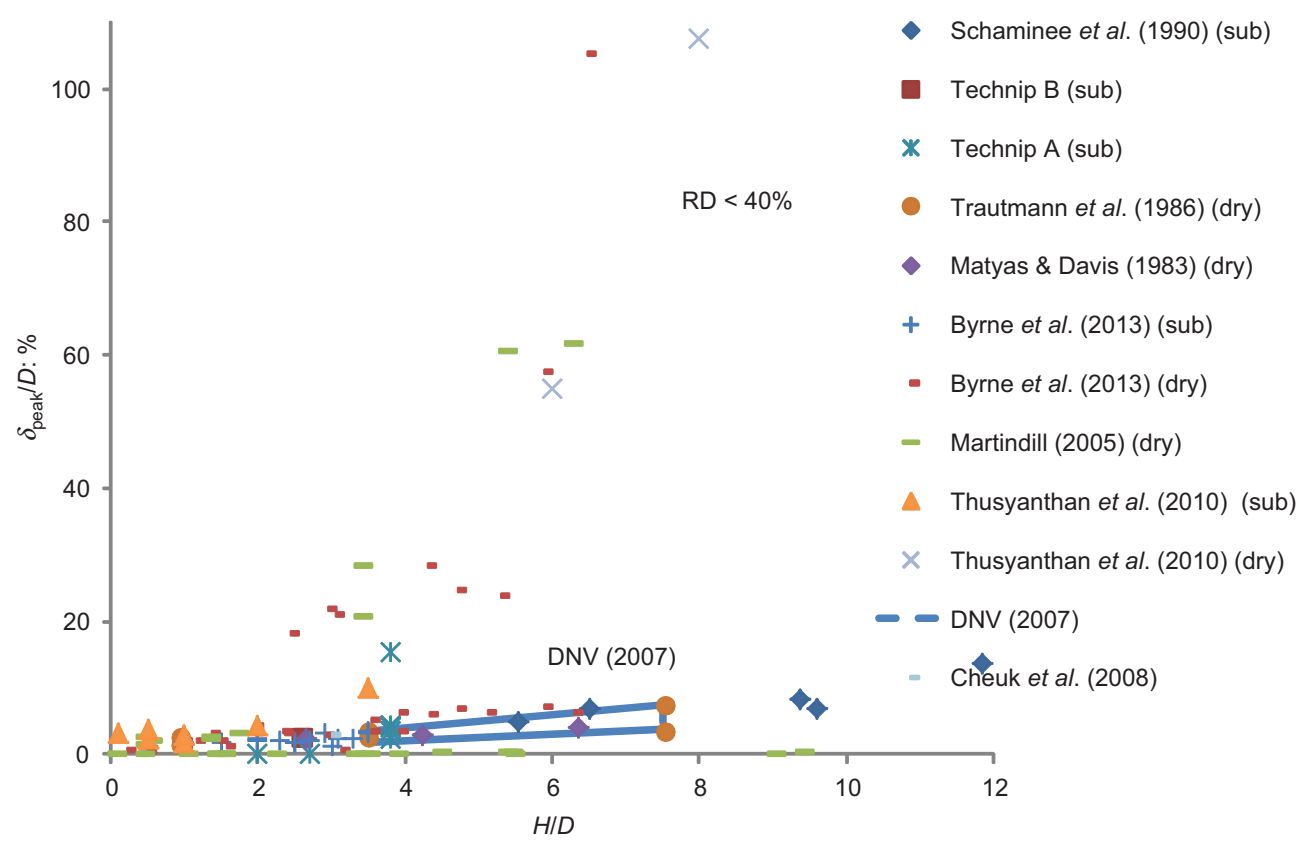

Fig. 2. Recommended mobilisation distance for loose sands normalised with pipe diameter (RD $<40 \%)$ - all data

submerged and dry soil conditions, respectively. Figure 2 shows that the majority of the data obtained from the Technip database fall within the shallow depth region $(H / D<3.5)$ for which DNV do not give recommendations. It is also clear from the results that higher values of mobilisation displacement are evident for dry conditions than submerged conditions

The sand used in all the studies was clean sand, apart from Technip B data where $10 \%$ of silt was present, in which case fully drained conditions may not have been realised. Bransby \& Ireland (2009) and Williams et al. (2013) comment on the importance of the test rate and the presence of the fines content in sand.

The curve proposed by Thusyanthan et al. (2010) and Wang et al. (2012) (equation (1)) takes into account test results from both dry and submerged conditions. As can be seen from Fig. 2, the dry condition data of Thusyanthan et al. (2010) are significantly higher for $H / D=6$ and $H / D=8$ and match only a few points obtained from other studies. This would suggest that if the proposed curve was recommended for design, the data for $H / D>3 \cdot 5$ would be overly conservative.

From Fig. 2 it is also clear that the experiments of Trautmann et al. (1986) and Matyas \& Davis (1983) undertaken in dry sand conditions are similar to those undertaken in saturated conditions. However, the studies undertaken more recently in dry conditions (Martindill, 2005; Thusyanthan et al., 2010; Byrne et al., 2013) indicate higher mobilisation displacements when compared with those undertaken in earlier studies.

The speed effect for the tests undertaken in saturated soil was examined and showed no significant influence on the peak mobilisation (Fig. 3). Since all the tests performed in saturated conditions were undertaken in loose soil and at

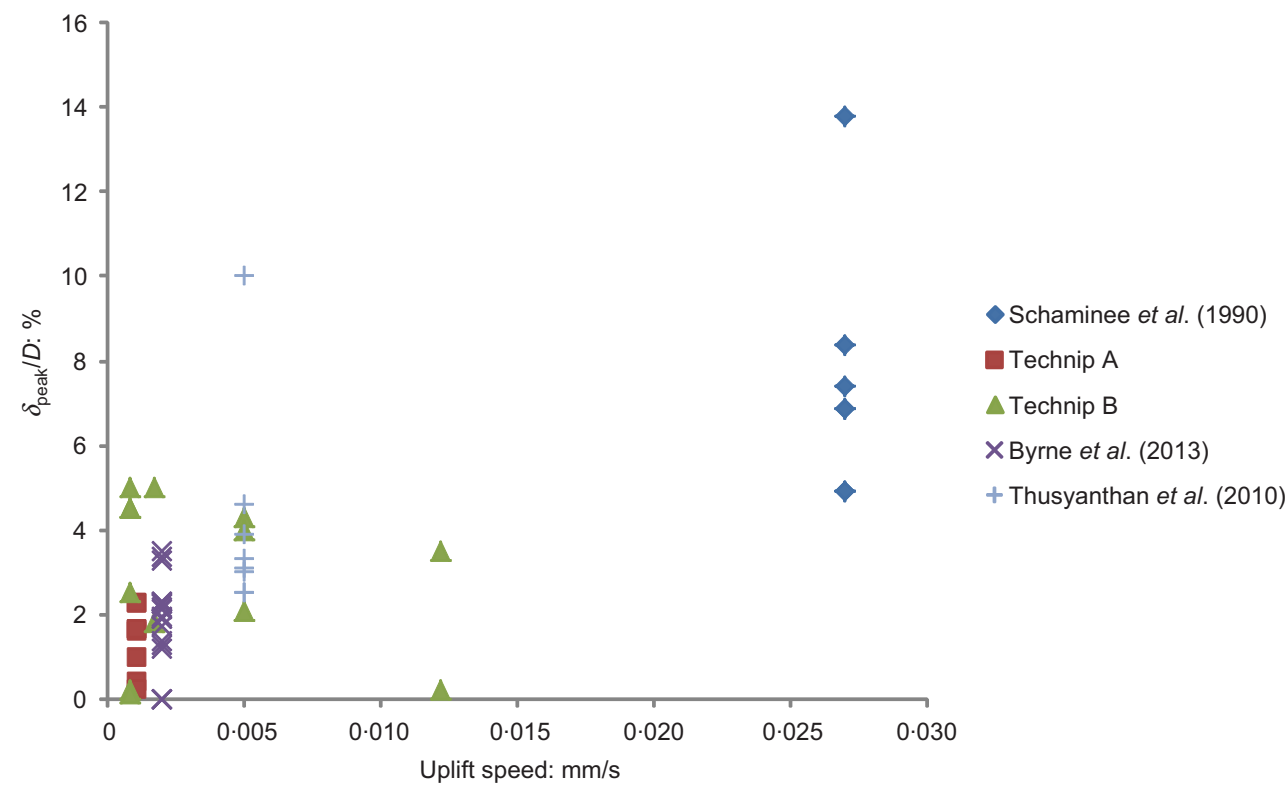

Fig. 3. Influence of uplift speed on mobilisation displacement for the cases undertaken in saturated sand 


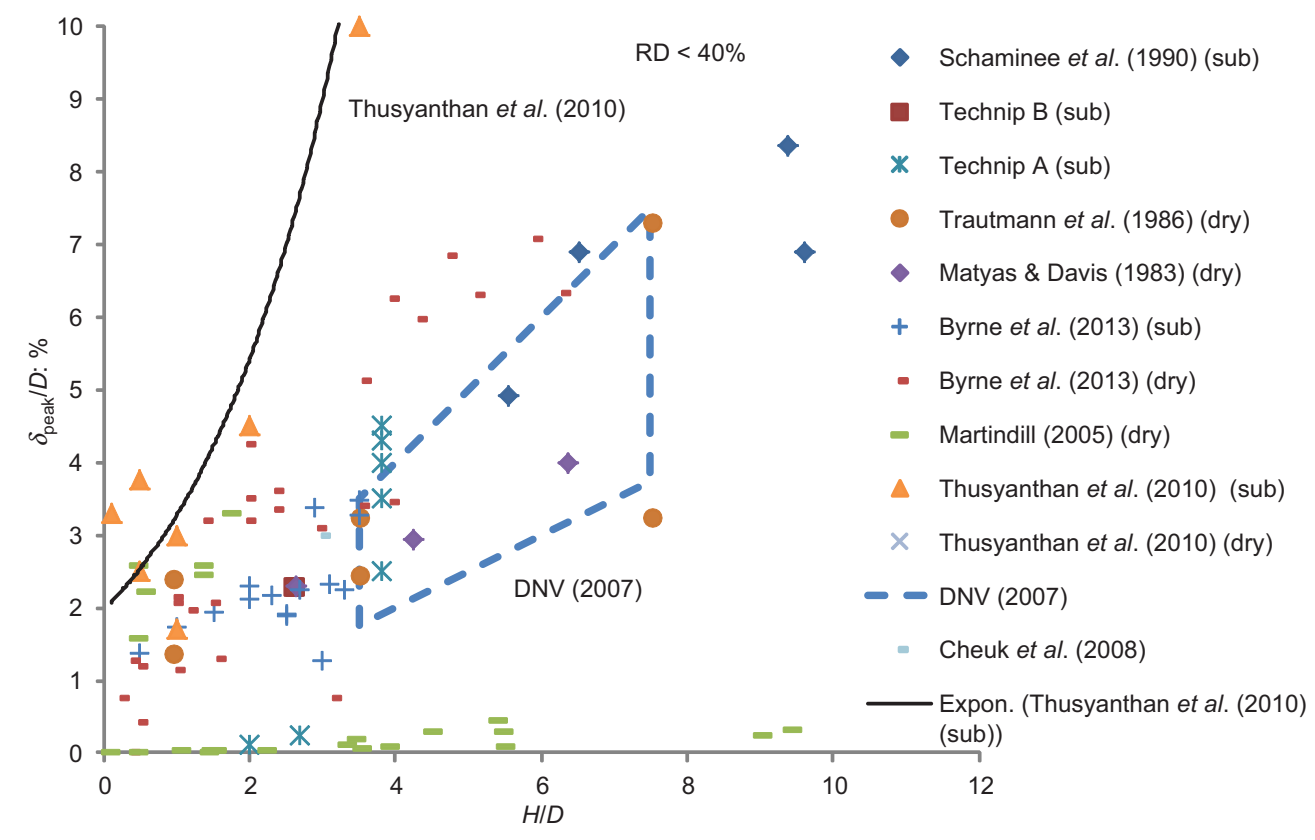

Fig. 4. Recommended mobilisation distance for loose sands normalised with pipe diameter (RD < 40\%)

uplift speeds less than $0 \cdot 167 \mathrm{~mm} / \mathrm{s}$, according to Bransby \& Ireland (2009) and Williams et al. (2013) the speed effect should not have been influential. Byrne et al. (2013) give 60 datasets for very loose sand $(\mathrm{RD}<10 \%$ ), representative of post-jetted sand providing strong evidence for the separate categorisation of very loose and loose sand.

\section{RECOMMENDATION}

It is clear that equation (1), proposed by Thusyanthan et al. (2010), does not best represent the data obtained from other studies for $H / D<3 \cdot 5$. It is clear that, for shallow depths, the mobilisation distance is different from that found for deeper trenching depths. It is also clear from Fig. 4 that very loose sand performs differently from loose sand. Consequently, the loose sand classification can be further separated into loose $(10 \%<\mathrm{RD}<40 \%)$ and very loose sand $(\mathrm{RD}<10 \%)$, associated with mechanically placed sand and post-lay jetting, respectively.

Figure 5 proposes an extension to the DNV zone where only data within the 'loose' sand range were considered. Figure 6, on the other hand, proposes an extension to the DNV zone where only data for very loose sand are presented. Here, the extension zone mainly captures the data reported by Byrne et al. (2013), currently the most comprehensive study in terms of very loose sand. The zone suggested goes beyond the recommended DNV zone for $3 \cdot 5<H / D<7 \cdot 5$ to include these data and also gives an extension for shallow depths.

This indicates that a further distinction within the DNV recommended practice is required in which very loose sand could follow a more conservative upper bound limit. This

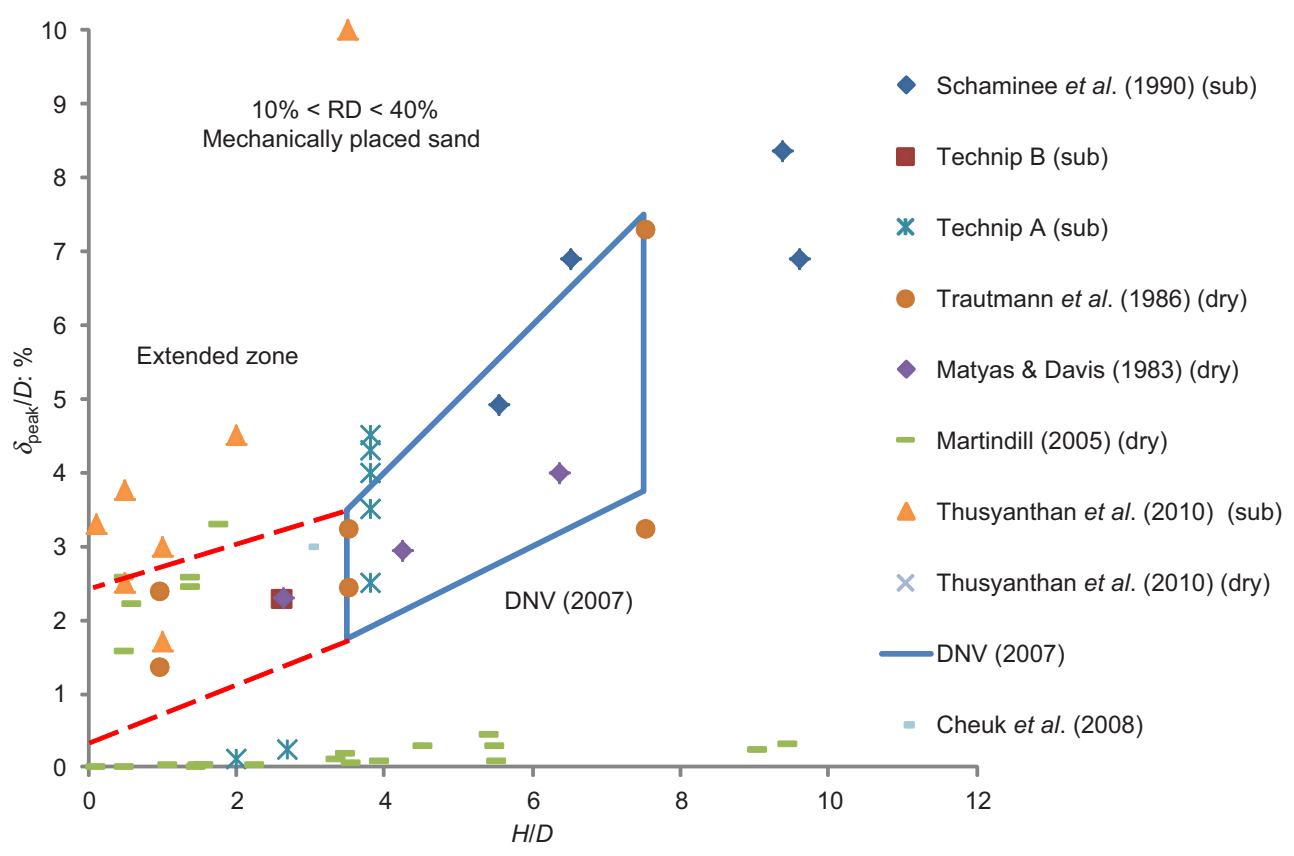

Fig. 5. New proposed mobilisation distance zone for loose sand, $10 \%<\mathrm{RD}<40 \%$ (mechanically placed sand) 


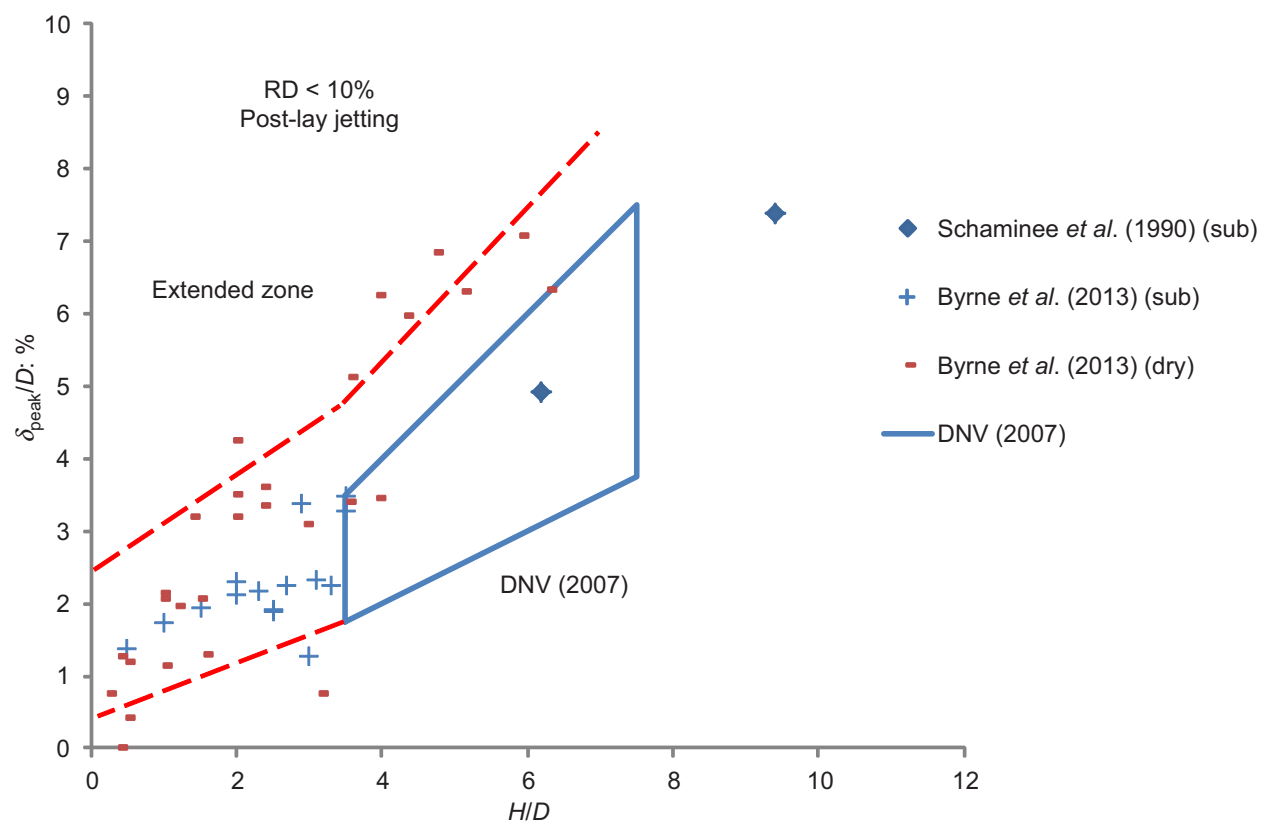

Fig. 6. New potential mobilisation distance zone for very loose sand, $\mathrm{RD}<10 \%$ (post-lay jetting)

assumes that the results of tests in dry conditions are sufficiently representative of the submerged soil conditions found in the field.

\section{CONCLUSIONS}

Mobilisation displacements associated with the uplift resistance of buried pipelines were examined and a comparison of the Technip database and the DNV recommendations was undertaken. The results of recent laboratory studies were taken into account, indicating the trends for shallow depths and a clear distinction between sets of tests undertaken in dry and submerged conditions. Following the analysis, it appears that the DNV code still provides suitable recommendations for higher $H / D$ values while some modifications are required for lower values, in particular to capture data from studies undertaken in recent years. A distinction is made between very loose and loose sand and new recommended peak mobilisation curves are proposed that better represent the two cases. It was also shown that, in the tests undertaken in saturated conditions, the uplift speed used should not influence the mobilisation displacement.

\section{REFERENCES}

Bransby, M. F. \& Ireland, J. (2009). Rate effects during pipeline upheaval buckling in sand. Proc. ICE - Geotech. Engng 162, No. 5, 247-256.

Bransby, M. F., Newson, T. A., Davies, M. C. R. \& Brunning, P. (2002). Physical modelling of the upheaval resistance of buried offshore pipelines. Proc. 1st Int. Conf. on Physical Modelling in Geotechnics, St. Johns, Newfoundland, 899-904.

Byrne, B. W., Schupp, J., Martin, C. M., Maconochie, A., Oliphant, J. \& Cathie, D. N. (2013). Uplift behaviour of shallowly buried pipe sections in saturated very loose sand. Géotechnique 63, No. 5, 382-390.

Cheuk, C. Y., White, D. J. \& Bolton, M. D. (2008). Uplift mechanisms of pipes buried in sand. ASCE J. Geotech. Geoenviron. Engng 134, No. 2, 154-163.

Dickin, E. A. (1994). Uplift resistance of buried pipelines in sand. Soils and Found. 34, No. 2, 41-48.

Dickin, E. A. \& Laman, M. (2007). Uplift response of strip anchors in cohesionless soil. Adv. Engng Software 38, No. 8-9, 618-625.
DNV (Det Norske Veritas) (2007). DNV-RP-F110: Global buckling of submarine pipelines - structural design due to high temperature/high pressure. Oslo: Det Norske Veritas.

Martindill, J. (2005). An investigation into the unburial behaviour of offshore pipelines. MEng project dissertation, Brasenose College, University of Oxford.

Matyas, E. L. \& Davis, J. B. (1983). Experimental study of earth loads on rigid pipelines. ASCE J. Geotech. Engng 109, No. 2, 202-209.

Ng, C. W. E. \& Springman, S. M. (1994). Uplift resistance of buried pipelines in granular materials. Centrifuge '94 (Lee, F. H., Leung, C. F. \& Tan, T. S. eds), 1. Rotterdam: Balkema, pp. 753-758.

Palmer, A. C., White, D. J., Baumgard, A. J. et al. (2003). Uplift resistance of buried submarine pipelines: comparison between centrifuge modelling and full scale tests. Géotechnique 53, No. $10,877-833$.

Randolph, M. \& Gourvenec, S. (2011). Offshore geotechnical engineering. London: Spon Press.

Schaminee, P. E. L., Zorn, N. F. \& Schotma, G. J. M. (1990). Soil response for pipelines upheaval buckling analysis: full scale laboratory tests and modelling. Proc. Offshore Technology Conf., Houston, TX, pp. 563-572, OTC 6486.

Technip OED (2003). Review of geotechnical aspects of UHB. Technip OED, Westhill, Internal report OE002006-R-001.

Thusyanthan, N. I., Mesmar, S., Wang, J. \& Haigh, S. K. (2010). Uplift resistance of buried pipelines and DNV-RP-F110. Proc. OPT 2010, Amsterdam, 24-25 February.

Trautmann, C. H., O'Rourke, T. D. \& Kulhawy, F. H. (1986). Uplift force-displacement response of buried pipeline. ASCE J. Geotech. Engng 111, No. 9, 1061-1076.

Wang, J., Haight, S. K., Forrest, G. \& Thusyanthan, I. (2012). Mobilisation distance for upheaval buckling of pipelines. ASCE J. Pipeline Syst. Engng Prac. 3, No. 4, 106-114.

White, D. J., Barefoot, A.J. \& Bolton, M. D. (2001). Centrifuge modelling of upheaval buckling in sand. Int. J. Phys. Model. Geotech. 1, No. 2, 19-28.

Williams, E. S., Byrne, B. W. \& Blakeborough, A. (2013). Pipe uplift in saturated sand: rate and density effects. Géotechnique 63, No. 11, 946-956.

\section{WHAT DO YOU THINK?}

To discuss this paper, please email up to 500 words to the editor at journals@ice.org.uk. Your contribution will be forwarded to the author(s) for a reply and, if considered appropriate by the editorial panel, will be published as a discussion. 